
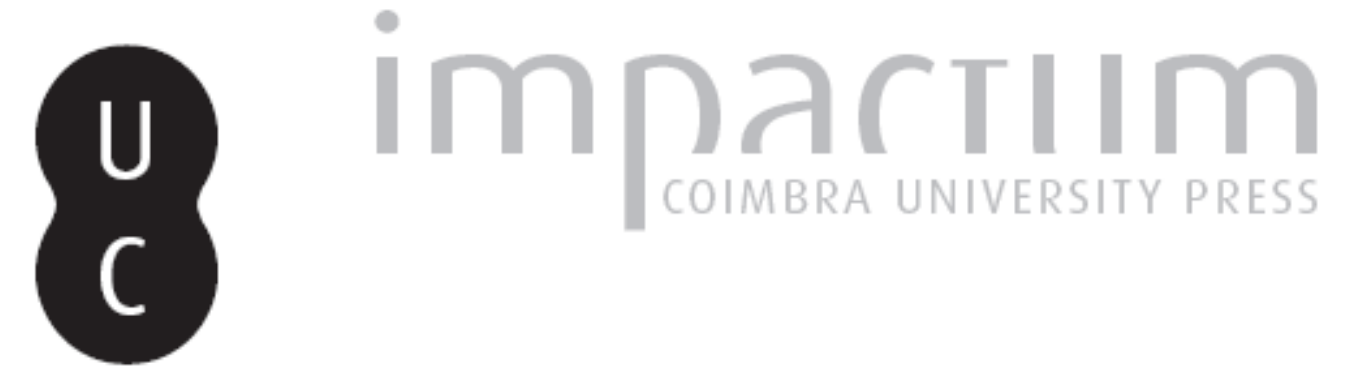

\title{
Santos e santidade: o período medieval
}

Autor(es): Costa, Bruno Abreu

Publicado por: Centro de História da Sociedade e da Cultura

URL persistente:

URI:http://hdl.handle.net/10316.2/39440

DOI:

DOI:http://dx.doi.org/10.14195/1645-2259_12_19

Accessed : $\quad$ 26-Apr-2023 10:34:20

A navegação consulta e descarregamento dos títulos inseridos nas Bibliotecas Digitais UC Digitalis, UC Pombalina e UC Impactum, pressupõem a aceitação plena e sem reservas dos Termos e Condições de Uso destas Bibliotecas Digitais, disponíveis em https://digitalis.uc.pt/pt-pt/termos.

Conforme exposto nos referidos Termos e Condições de Uso, o descarregamento de títulos de acesso restrito requer uma licença válida de autorização devendo o utilizador aceder ao(s) documento(s) a partir de um endereço de IP da instituição detentora da supramencionada licença.

Ao utilizador é apenas permitido o descarregamento para uso pessoal, pelo que o emprego do(s) título(s) descarregado(s) para outro fim, designadamente comercial, carece de autorização do respetivo autor ou editor da obra.

Na medida em que todas as obras da UC Digitalis se encontram protegidas pelo Código do Direito de Autor e Direitos Conexos e demais legislação aplicável, toda a cópia, parcial ou total, deste documento, nos casos em que é legalmente admitida, deverá conter ou fazer-se acompanhar por este aviso.




evista de História da Sociedade e da Cultura



Centro de História da Sociedade e da Cultura Universidade de Coimbra 


\title{
Santos e Santidade. O período medieval ${ }^{1}$
}

\author{
Bruno Abreu Costa \\ Estudante da Licenciatura de História da FLUC \\ brunoacosta@portugalmail.pt
}

\section{Resumo/Abstract:}

A presente notícia assume-se como uma síntese bibliográfica subordinada à temática da santidade, mormente no período medieval e no espaço ibérico. Dessa forma, procura mostrar, em traços gerais, uma definição dos conceitos de "santo" e de "santidade", apresentando variados modelos de santidade e as suas principais características. Numa segunda parte, é focado o culto ao santo, expondo diversas teorias sobre as suas origens e algumas modalidades praticadas.

The present review article aims to be a bibliographical synthesis on the theme of sanctity, especially in the medieval time. The purpose is to describe, in general features, the definition of "saint" and "sanctity", showing the different kind of role models of sanctity and their main characteristics. Afterwards, the focus is giving to the cult of the saints, explaining the several theories about the origin and some of the practices of the cult.

Palavras chave/Keywords:

Santidade medieval; Modelos de santidade; Culto ao santo; Romarias; Peregrinações.

Medieval sanctity; Role models of sanctity; Cult of the saint; Pilgrimages.

1 Não seria possível conceber este trabalho sem o apoio da Professora Doutora Maria Teresa Nobre Veloso, nossa orientadora. A ela o nosso bem-haja. 


\section{Bolsas de Integração na Investigação para Estudantes do Ensino Superior}

Procurando responder ao Compromisso com a Ciência, assumido pelo Governo Português, e nos termos do Regulamento da Formação Avançada e Qualificação de Recursos Humanos, a Fundação para a Ciência e a Tecnologia (FCT), lançou, em 2009 e 2010, um Concurso de Bolsas de Integração na Investigação para Estudantes do Ensino Superior. O Centro de História da Sociedade e da Cultura (CHSC) seleccionou, em duas fases do concurso, vinte Estudantes da área da História.

Conforme constava do respectivo Regulamento das Bolsas de Integração na Investigação, os bolseiros estavam obrigados a elaborar, no final do tempo de aprendizagem, um pequeno Relatório Científico. O CHSC procedeu à discussão de alguns desses Relatórios, na presença de um júri, que apreciou, classificou e sugeriu alterações ou desenvolvimentos quanto ao trabalho produzido.

Agora, através da sua "Revista de História da Sociedade e da Cultura", vai mais longe e, com a finalidade de premiar, decidiu encetar a publicação dos trabalhos que merecem ser distinguidos. É o caso de Santos e Santidade. O período medieval, de Bruno Abreu da Costa, orientado pela Professora Doutora Maria Teresa Nobre Veloso.

Coimbra, 24 de Setembro de 2012

O Coordenador Científico do CHSC João Marinho dos Santos 
O trabalho que apresentamos constitui uma súmula do relatório realizado enquanto bolseiro do Centro de História da Sociedade e da Cultura (CHSC) da Faculdade de Letras da Universidade de Coimbra, e da Fundação para a Ciência e Tecnologia (FCT), no âmbito das Bolsas de Integração à Investigação (BII). O citado relatório recebeu nota máxima atribuída pela orientadora do trabalho, Professora Doutora Maria Teresa Nobre Veloso, e pelo Coordenador Científico do CHSC, Professor Doutor João Marinho dos Santos.

O relatório irá, futuramente, constituir o capítulo introdutório de um trabalho subordinado à temática hagiográfica, visto que aborda questões ligadas à definição de santo, santidade e culto, num contexto muito genérico. Por esta razão, o presente relatório servirá como ponto de partida para futuros trabalhos, mais aprofundados.

Muitos se questionam o porquê desta temática e a escolha da mesma. A esses respondemos que este tema abrange variados aspectos do mundo medieval: situações relacionadas com a mentalidade e religiosidade (exemplificados pelas peregrinações/romarias na busca da salvação), na cultura (através das hagiografias e obras artísticas em torno do culto ao santo), questões económicas (as feiras realizavam-se na sequência de uma romaria e frequentemente adquiriam o nome do santo, sem esquecer que o pagamento de variados serviços e rendas eram efectuados num dia específico - comummente no dia de S. João ou de S. Miguel) e até políticos (não convém esquecer que a Igreja era e é uma grande instituição, além de que no período medieval podemos defender a existência de uma teocracia papal plena). Actualmente a importância dos santos sobrevive e manifesta-se ainda no nosso nome próprio, que continua a evocar a memória daqueles que foram mais cultuados. Não serão as festas de Santo António, S. João e S. Pedro - os ditos "Santos Populares" - um dos momentos mais festivos celebrados por toda a cristandade, mobilizando a população para o convívio social?

Em relação à metodologia utilizada, é necessário compreender que o projecto que apresentámos passou por várias fases distintas, mas complementares. A primeira consistiu na consulta de vários números (28 no total - de 1947 até $1961^{2}$ ) da revista Archivos Leoneses - revista bienal

2 Foram consultados até ao Tomo XV, vol. 29-30. No entanto, por motivos desconhecidos, os volumes 21 e 26 não se encontravam disponíveis na FLUC. 
do "Centro de Estudios e Investigación San Isidoro", com sede em León, Espanha - procurando artigos relativos a "santos", "santidade", "mosteiros e "vida monástica". A escolha desta revista em particular prende-se com a proximidade geográfica entre a Galiza e Portugal, em relação à sua história medieva e aos cultos cristãos praticados nos respectivos territórios. Sobre as temáticas em questão foram consultados 40 artigos, os quais podem ser divididos de acordo com a sua tipologia, tal como o demonstra a tabela 1 .

Tabela 1 - Número de artigos segundo o seu género

\begin{tabular}{|l|c|}
\hline \multicolumn{1}{|c|}{ Tipologia dos Artigos } & $\begin{array}{c}\text { Número de artigos existentes } \\
\text { sobre as temáticas referidas }\end{array}$ \\
\hline Artigos Historiográficos/Narrativos & 24 \\
\hline Catálogos de Documentos & 3 \\
\hline Publicação de Documentos & 5 \\
\hline $\begin{array}{l}\text { Resenhas Bibliográficas ou } \\
\text { Recensões Críticas }\end{array}$ & 8 \\
\hline & Total
\end{tabular}

A revista Archivos Leoneses tornou-se de extrema importância para levar a cabo um acréscimo do conhecimento sobre a cultura medieval e mormente sobre a santidade na mesma época. A citada revista possui um cariz temático. Os seus artigos abordam inúmeras questões ligadas à mentalidade e, em especial, à Igreja, dando uma atenção muito particular à santidade. Os Archivos Leoneses constitui-se como bibliografia fundamental para o estudo da mentalidade medieva, particularmente na Península Ibérica, com especial destaque para a Galiza e Leão. Incontornável pelos seus interessantes artigos, tal como é o caso daqueles assinados por Luís López Santos, esta revista teve o seu término no final do século passado, legando-nos cerca de seis décadas de estudos importantíssimos sobre a temática aqui abordada.

Numa segunda fase, procurámos a bibliografia sobre a temática específica do trabalho - os santos e a santidade - de preferência relativos à Idade Medieval e à Península Ibérica. No entanto, não quisemos colocar esses limites - cronológico e geográfico - no início da nossa investigação, de modo a recolher uma concepção abrangente da santidade cristã ao longo de vários séculos. 
Após estas duas fases preparatórias, tivemos necessidade de deixar o geral e restringir cada vez mais o objecto de estudo, de modo a chegar ao particular. A terceira fase - por vezes em sincronia com a etapa anterior baseou-se na criação de um rol hagiográfico, através dos artigos dos Archivos Leoneses consultados.

A última etapa do projecto é composta pela organização e redacção do trabalho escrito, cuja síntese aqui apresentamos.

Esta súmula segue a apresentação do relatório e divide-se em dois capítulos principais. O primeiro trata os santos e a santidade numa perspectiva alargada. O capítulo 2 - "O Culto ao Santo" - apresenta a matéria relacionada com o culto destas personalidades.

\section{1 - O Santo e a Santidade}

Comecemos com a definição de santo. "Adjectivo, aquele que foi canonizado e/ou a quem os fiéis rendem culto; aquele que é puro, isento de culpa; por extensão diz-se de pessoa virtuosa, bondosa, de conduta exemplar, irrepreensível; ou aquele que é digno de veneração e respeito"3.

O vocábulo sanctu/sancti aparece na Bíblia para designar os próximos de Deus, o povo de Israel e as figuras exemplares, sendo a santidade uma característica do próprio Deus:

"Loquere ad omnem cœtum filiorum Israel, et dices ad eos: a sancti estote, quia ego sanctus sum, Dominus Deus vester"4.

Com Cristo a santidade desce à terra, englobando todos os fiéis:

"Eclesiæ Dei quæ est Corinthi, sanctificatis in Christo Jesu, vocatis sanctis, cum omnibus qui invocant nomem Domini nostri Jesu Christi, in omni loco ipsorum, et nostro"s.

3 Santo in Dicionário Houaiss da Língua Portuguesa, vol. III. Lisboa: Temas e Debates, 2003.

4 Levítico 19, 2: "Diz a toda a comunidade dos filhos de Israel: sede santos, porque Eu, o Senhor, vosso Deus, sou santo.” Veja-se também a passagem do Levítico 20, 26.

51 Coríntios, 1, 2: “À Igreja de Deus que está em Corinto. Dirigimo-nos àqueles que foram santificados em Cristo Jesus, e chamados santos, juntamente com todos os que invocam em todo o lugar o nome de Nosso Senhor Jesus Cristo, Senhor deles e nosso". 
Desta forma, Jesus Cristo torna-se modelo de santidade; ilação retirada após uma cuidadosa análise da literatura hagiográfica dos primeiros tempos do Cristianismo, sendo os textos, claramente, "cristocêntricos", isto é, inspirados na vida de Cristo, apresentando o novo santo como uma Imitatio Christi. Seguindo o Salvador, o santo torna-se modelo de fé, virtude, amor, oração e de sacrifício próprio, não seguindo um objectivo de felicidade pessoal ${ }^{7}$. Ele é uma testemunha da fé; mais, é um modelo de humanidade cristã $\tilde{a}^{8}$ Santo não é aquele que por um acto esporádico é trazido aos altares, é elevado pela continuidade das suas acções quotidianas.

Não nos podemos esquecer que, como nos diz o Cardeal José Saraiva Martins ${ }^{9}$, outrora Prefeito da Congregação para a Causa dos Santos, o santo é composto pela agregação de duas vertentes, a humana e a celestial. A última expõe o santo como alguém já falecido, encontrando-se no "Reino de Deus", na "Corte Celestial"; a primeira apresenta-nos uma pessoa que viveu, que foi real, que existiu. Enfim, "saints are anyway, real and historical persons, who survive, not just as memories, but as forces, and do so, because they had something special in them (...)"10, tornando-se, por isso, modelo de humanidade.

Sofia Boesch Gajano percepciona a santidade como um fenómeno que abrange cinco dimensões distintas: a dimensão teológica, onde a santidade é a manifestação de Deus no mundo; o fenómeno religioso, que proporciona um momento privilegiado e uma relação com o sobrenatural; a dimensão

6 PETRI, Charles - L'Évolution du Cult des Saints aux Premiers Siècles Chrétiens: du témoin à l'intercesseur, in Les Fonctions des Saints dans Le Monde Occidental (III ${ }^{e}$-XIII ${ }^{e}$ Siècle), Actas du colloque organisé par l'École Française de Rome avec le concours de l'Université de Rome «La Sapienza». Roma: École Française de Rome, 1991, p. 23.

7 "A felicidade com frequência é associada ao egoísmo de uma vida prazerosa e a vida prazerosa com frequência se vincula à vida neste mundo", in CABRAL, Mário Via Sapientiae: da filosofia à santidade. Lisboa: Imprensa Nacional-Casa da Moeda, 2008, p. 329; devido a este facto, o santo não se relaciona com a felicidade pessoal, mas sim com a vida de sacrifício pessoal e pelos outros.

8 "Ser cristão é ser santo. Ou ser santo é simplesmente ser cristão a sério", in OLIVEIRA, José H. Barros - Santos de todos os Tempos: Vinte séculos de Santidade. s. 1.: PAULUS Editora, 2003, p. 5.

9 MARTINS, José Saraiva e GAETA, Saverio (entrevistador) - Como se faz um Santo. s.1.: Alêtheia Editores, 2006, p. 14 e ss.

${ }^{10}$ MARTINDALE, C.C. - What are Saints? Fifteen chapters in sanctity. London: Sheed \& Ward, 1935 (Conferências na BBC, desde 24 de Janeiro até 8 de Maio de 1932), p. 18. 
social, como factor de coesão e identificação de grupos e comunidades; a dimensão institucional, sendo esta a base da estrutura eclesiástica e monástica; e, por último, a dimensão política, devido à confluência entre o poder eclesiástico e o laico ${ }^{11}$.

A santidade, enquanto título, é um adjectivo, uma "condecoração honorífica" atribuída após o processo de canonização; como se de uma recompensa se tratasse por uma vida de virtude e amor ao próximo e a Deus. Igualmente entende-se a santidade como um processo em construção ${ }^{12}$, pois é o ser humano que edifica a sua própria santidade, optando pelo caminho "correcto" e praticando actividades terrenas e espirituais (boas obras).

O processo de canonização corresponde à transfiguração do ordinário em cânone, ou do comum num paradigma. Ou pelo menos compreende o reconhecimento dessa passagem.

Era a vox populi, a "voz do povo", que proclamava a santidade de um cidadão excepcional. Esta sacralização era depois ratificada, ou não, pela canonização oficial da Igreja ${ }^{13}$.

A partir de 1050 - com o início da Reforma de Gregório VII - começou-se a exercer um controlo mais rígido sobre os homens "ilustres" que serão conduzidos ao altar. No entanto, é a partir da primeira metade do século XIII, com Gregório IX, que o papado exerce o "controlo sobre as virtudes e os milagres dos servidores de Deus"14 - a tal "fábrica de santos", analisada por Jean-Claude Schmitt ${ }^{15}$ - principiando a procura de provas de santidade e elaborando exames e análises à vida do candidato.

Durante toda a história do Cristianismo - e principalmente na época medieval - ocorrem ciclos de santidade, isto é, períodos em que um modelo de santidade impera sobre os outros ${ }^{16}$.

${ }^{11}$ BOESCH GAJANO, Sofia - Santidad, in LE GOFF, Jacques e SCHMITT, Jean-Claude (edit.), Diccionário Razonado del Occidente Medieval. s.l.: Akal Ediciones, 2003, p. 711.

${ }^{12}$ BOESCH GAJANO, Sofia - Santidad, cit, p. 711.

${ }^{13} \mathrm{O}$ que vai gerar dois tipos de santos: os reconhecidos pela Igreja e com culto na Cristandade Universal, e os não reconhecidos, com culto apenas local.

${ }^{14}$ VAUCHEZ, André - O Santo, in LE GOFF, Jacques (dir.), O Homem Medieval. Lisboa: Editorial Presença, 1989, 211-230.

${ }^{15}$ SCHMITT, Jean-Claude - La Fabrique des Saints. Annales. Économies, Sociétés, Civilisations, 39e année, no 2 (1984), 286-300.

${ }^{16}$ VAUCHEZ, André - O Santo, cit., p. 212. 
Sucintamente, a Idade Média conheceu o ciclo dos mártires, seguindo-se o dos confessores, dos santos bispos, dos nobres e dos monarcas, dos monges, e por último, dos místicos e pregadores. A santidade ganha pelo trabalho - o santo trabalhador - é a última conquista. Com o início da Idade Moderna a questão dos "ciclos de santidade" esfuma-se, não se tornando claros os períodos de predominância na ascensão à "Corte Celestial".

Em relação às funções do santo, podemos afirmar que elas são de quatro tipos: de intercessão, de intervenção, de companhia e de modelo.

A principal função do santo é interceder perante Deus em favor do crente, de forma a garantir uma "boa morte" e uma passagem rápida para o paraíso e para a salvação.

No entanto, este era um serviço nada gratuito. O crente teria de demonstrar o seu esforço, realizando peregrinações até ao túmulo do santo ou então oferecendo a este algum ex-voto ${ }^{17}$.

O intercessor também actua directamente na vida do "seu crente", exorcizando demónios, curando doenças, afastando a pobreza e a guerra, resolvendo conflitos entre o Homem e a Natureza e entre os Homens, ou até através de poderes proféticos que se manifestavam aos crentes em visões e sonhos ${ }^{18}$. Isto porque o santo tinha a capacidade de "lire dans le cœur des hommes et de voir clair dans les événements"19.

O santo é, nas palavras de Peter Brown, a "companhia invisível"20, cuja função é idêntica à do "anjo-da-guarda", cuidando do indivíduo, desde o nascimento até à sua morte, de forma íntima. Assim o santo aparece como um patronus - o protector, o padroeiro - exercendo o papel de "defensor, protector e inspirador de uma comunidade"21.

${ }^{17}$ Lembremo-nos da peregrinação do rei Roberto de que nos fala DUBY, Georges O Ano Mil. Lisboa: Edições 70, 1992, p. 154 e 155.

${ }^{18}$ Como é o caso de S. Martinho de Tours, que aparece numa visão a Hervé, in DUBY, Georges - O Ano... cit., p. 154 e 155.

19 VAUCHEZ, André - Saints, Prophètes et Visionnaires. Le pouvoir surnaturel au Moyen Age. Paris: Albin Michel, 1999, p. 26.

${ }^{20}$ BROWN, Peter - The Cult of Saints. Its Rise and Function in Latin Christianity. Chicago: The University of Chicago Press, 1982, p. 50 e ss.

${ }^{21}$ MARTINS, José Saraiva e GAETA, Saverio (entrevistador) - Como se faz..., cit., p. 60 . 
A forma íntima, que foi referida anteriormente, deve-se ao papel do santo como protector pessoal do crente; este, por vezes, tem o nome do seu santo protector, seja por ter nascido no dia em que se celebra o dies natalis do "ser excepcional", seja por devoção particular da família do recém-nascido. Por vezes, o santo é escolhido por ambos, protector e protegido, terem pertencido à mesma comunidade profissional, como é o caso dos santos padroeiros de confrarias que "ganham" o culto de todos os confrades, ou os santos padroeiros de uma determinada profissão.

Por último, o venerável tem a função de modelo de vida para o fiel, como exemplo de uma salvação alcançável.

Tal como nos diz Maria Helena da Cruz Coelho, "a relação do crente com os santos é complexa, tecida de sentimentos contrários, que oscilam entre o temor e o respeito" 22 . O crente invoca o santo e roga-lhe um favor, prometendo logo uma oferenda - normalmente uma peregrinação - e criando assim uma relação. Assim, "o que precisa invoca, pede, promete. O santo dá e recebe. O que, no limite, leva a um certo mercadejar com os santos"23.

A importância do santo no período medieval associa-se com o carácter frágil do homem e da mulher na época. A alimentação débil, o temperamento impetuoso dos homens - que gera guerra - e a fraca resistência a doenças e epidemias fazem do ser humano medieval um ser que necessita de um apoio tranquilizador ${ }^{24}$. Ainda mais, o "amigo invisível" ajudaria a suportar o fardo da vida terrena e a concretizar uma "boa morte", que se saldaria pela salvação.

Além de exemplo de vida, o santo era um "concidadão"25 tornando-se factor de integração e de coesão numa comunidade ou confraria.

${ }^{22}$ COELHO, Maria Helena da Cruz - Superstição, Fé e Milagres na Idade Média. Coimbra: INATEL e Secretaria de Estado da Cultura, 1995, p. 29 e ss.

${ }^{23}$ COELHO, Maria Helena da Cruz - Superstição..., cit., p. 29 e ss.

${ }^{24}$ BOESCH GAJANO, Sofia - Santidad, cit., p. 712.

25 "Os mártires e os santos locais cujas sepulturas eram visitadas regularmente e cujos aniversários de morte eram celebrados por festivais oficiais, eram, de facto, «concidadãos». Com efeito, os santos tinham em tempo rezado na igreja local pelo povo cristão da cidade", como nos diz BROWN, Peter - A Ascensão do Cristianismo no Ocidente. Lisboa: Editorial Presença, 1999, p. 80. 
Por outro lado, não nos podemos esquecer que o culto a determinado santo, originando uma festa ou feira, significaria uma interrupção na dura vida do trabalho do campo e num escape para a monotonia do quotidiano.

Assim, o santo, entidade constante ao longo destes vinte e um séculos de Cristianismo, sempre foi um anjo-da-guarda para o "seu" crente. Por intercessão ou intervenção directa, o "ser de excepção" ajuda o homem comum a pensar na recompensa da sua vida de trabalho árduo, dando-lhe um exemplo, através do seu próprio comportamento, de como alcançar a tão desejada salvação.

\section{2-O Culto ao Santo}

P. Saintyves ${ }^{26}$ defende a tese dos santos "como sucessores dos deuses", sublinhando as coincidências formais do culto aos santos. Explicitando, este autor verificou uma continuidade no uso dos lugares de culto ao sagrado da Antiguidade - nascentes, penedos e bosques. Assim, estes lugares tanto eram usados no culto de santos, como no culto a "génios" ou "semi-deuses", praticado por galo-romanos e que se prolongou até à Idade Média Tardia. No entanto, já desde o século IV teólogos como Santo Agostinho rejeitam a ideia de os santos poderem ser vistos como os sucessores dos deuses ou como deuses independentes ${ }^{27}$ :

"Eles [mártires] não são deuses: o Deus deles é o nosso Deus. É certo que veneramos as suas «memórias» como santos homens de Deus, que até à morte combateram pela verdade para fazerem conhecer a verdadeira religião, provando a falsidade, a mentira do paganismo"28.

André Vauchez não nega as hipóteses colocadas pelos autores anteriores, atestando que a santidade não poderia ser um conceito ex-nihilo e que aquela descenderia, então, de preceitos da Antiguidade.

${ }^{26}$ SAINTYVES, P. - Les Saints Successeurs des Dieux. Paris, 1907, citado por PETRI, Charles - L'Évolution..., cit., p. 15.

${ }^{27}$ SCHMITT, Jean-Claude - La Fabrique ..., cit., p. 287.

${ }^{28}$ Santo AGOSTINHO - Cidade de Deus, Vol. I. Lisboa: Fundação Calouste Gulbenkian, 1991-1995, Livro VIII, Cap. XXVII, p. 788. 
Peter Brown apresenta uma tese um pouco diferente das anteriores. O culto começaria por uma devoção particular, provavelmente ligada ao conhecimento pessoal do santo, que depois se estenderia à comunidade, seguida da aprovação pelo clero responsável e alastrando-se posteriormente por toda a cristandade.

Apesar da sua teoria, este autor, numa perspectiva mais pragmática, mas com algum fundo de verdade diz-nos que "the cult of the saints was the natural result of men who (...) had hoped, by multiplying intercessors on their behalf, to find an easier road to Heaven than the straight and narrow path they had been offered by the early Christian communities" 29 .

Existem variados tipos de culto ao santo no período medieval. No entanto, para o pedido de intercessão ou intervenção directa ser aceite, convinha que o culto se celebrasse no dia da morte terrena do santo. Comemorando, assim, o nascimento para a vida espiritual, o dies natalis.

No dies natalis de um santo, este era agraciado com os mais diversos tipos de culto: leitura da sua hagiografia na igreja, mosteiro ou confraria de que era padroeiro, devoção privada de uma família ou evocação nas cerimónias litúrgicas daquele dia. A data festiva atingia, porém, o seu auge com a realização de feiras, romarias e peregrinações que atraíam os fiéis e os congregavam à volta das relíquias desse ser excepcional. Com este fim, aqueles venciam distâncias, ultrapassavam dificuldades inauditas (obstáculos geográficos e climáticos), iludiam a fome, a sede e os ataques de animais e muitas vezes dos homens, com um único fim - obter graças. As dificuldades da viagem superavam-se na alegria do reencontro e faziam antever uma outra alegria - o chegar à "Jerusalém Celeste".

\section{Conclusão}

Chegámos ao fim do nosso trabalho e resta-nos sintetizar o que foi abordado ao longo destas páginas.

Assim, inferimos que o santo, independentemente do período em que foi canonizado ou do modelo de santidade em que se insere, é um

${ }^{29}$ BROWN, Peter, The Cult..., cit., p. 67. 
"ser de excepção". Um ser dual, uma pessoa real e histórica, que pelas suas continuadas boas acções, se torna num exemplo a seguir e num elo de ligação entre o terreno e o celestial.

O santo possui várias funções: a de intercessão, a de intervenção directa, a de "companhia invisível" ou "anjo-da-guarda", e a de modelo de vida para o crente, modelo de coragem, fortaleza e virtude, exemplificando a possibilidade da salvação, tão fundamental para o homem medievo.

Tal como foi referido, são múltiplos os tipos de cultos praticados ao santo: desde a devoção privada, a leitura da hagiografia, as cerimónias litúrgicas, mais ou menos sumptuosas no seu dies natalis, o culto de relíquias e a consequente peregrinação ou/e romaria, culminando num padroado realizado por igrejas, mosteiros e congregações.

Pretendemos que este trabalho venha a ser aprofundado, trazendo esses desenvolvimentos do tema ao prelo num futuro que se espera próximo. 